\title{
Nymphaeol-A Isolated from Okinawan Propolis Suppresses Angiogenesis and Induces Caspase-Dependent Apoptosis via Inactivation of Survival Signals
}

\author{
Ikumi Tsuchiya, ${ }^{1}$ Takahiro Hosoya, ${ }^{1}$ Motoko Ushida, ${ }^{1}$ Kazuhiro Kunimasa, ${ }^{2}$ \\ Toshiro Ohta, ${ }^{1}$ and Shigenori Kumazawa ${ }^{1}$ \\ ${ }^{1}$ Department of Food and Nutritional Sciences, University of Shizuoka, 52-1 Yada, Suruga-ku, Shizuoka 422-8526, Japan \\ ${ }^{2}$ Cancer Chemotherapy Center, Japanese Foundation for Cancer Research, 3-10-6 Ariake, Koto-ku, Tokyo 135-8550, Japan
}

Correspondence should be addressed to Toshiro Ohta; ohtat@u-shizuoka-ken.ac.jp and

Shigenori Kumazawa; kumazawa@u-shizuoka-ken.ac.jp

Received 10 January 2013; Revised 1 April 2013; Accepted 1 April 2013

Academic Editor: José Maurício Sforcin

Copyright (C) 2013 Ikumi Tsuchiya et al. This is an open access article distributed under the Creative Commons Attribution License, which permits unrestricted use, distribution, and reproduction in any medium, provided the original work is properly cited.

\begin{abstract}
Propolis, a resinous substance that honeybees collect to protect their beehive from enemies, is reported to have various biological activities. In our screening program to search for antiangiogenic compounds from propolis, the ethanol extracts of Okinawan propolis (EEOP) showed significant antiangiogenic activities in a tube formation assay with human umbilical vein endothelial cells (HUVECs) in vitro at $3.13 \mu \mathrm{g} / \mathrm{mL}$ and chorioallantoic membrane (CAM) assay in vivo at $25 \mu \mathrm{g} / \mathrm{egg}$. To elucidate the active compounds of EEOP and their mode of action, we isolated some prenylated flavonoids from EEOP and found that nymphaeol-A had the strongest antiangiogenic activity among them. Nymphaeol-A significantly reduced in vivo neovessel formation in the CAM assay at $25 \mu \mathrm{g} / \mathrm{egg}$. At the molecular level, nymphaeol-A markedly inactivated mitogen-activated protein kinase/ERK kinase 1/2 (MEK1/2) and extracellular signal-regulated kinase 1/2 (ERK1/2), whose molecular activations signal new vessel formation in HUVECs. In addition, nymphaeol-A dose- and time-dependently induced caspase-dependent apoptosis in tube-forming HUVECs. Taken together, nymphaeol-A was shown to inhibit angiogenesis at least in part via inactivation of MEK1/2-ERK1/2 signaling and induction of caspase-dependent apoptosis. Okinawan propolis and its major component, nymphaeol-A, may be useful agents for preventing tumor-induced angiogenesis.
\end{abstract}

\section{Introduction}

Angiogenesis is defined as the process of forming new blood vessels from preexisting ones. Folkman first observed that the angiogenesis is required for tumor growth in 1971 [1]. Tumor-induced neovessels carry oxygen and nutrients into tumor tissues and function as the primary path of metastasis. Cutting off the blood supply of oxygen and nutrients to solid tumors represents a useful antiangiogenic therapy for tumors. Bevacizumab, a monoclonal antibody that binds to vascular endothelial growth factor (VEGF), was developed as an antiangiogenic drug for colon cancer treatment. In recent years, various antiangiogenic inhibitors have been developed, used in clinical trials, and approved for a number of cancer treatments. Antiangiogenic treatment may be useful in the treatment and prevention of cancer progression.

Propolis, a resinous substance collected by honeybees from the buds and exudates of certain trees and plants, is stored inside their hives and has been used in folk medicines from ancient times in many regions. It has been reported to have various biological activities such as antioxidant [2], antibacterial [3], antiviral [4], antifungal [5], anti-inflammatory [6], and anticancer [7] activities. In general, propolis is known to have various chemical compositions depending on the vegetation at the site of its collection. For example, propolis from Europe and China contains many kinds of flavonoids and phenolic acid esters. In contrast, propolis from 
Brazil contains terpenoids and prenylated derivatives of $p$ coumaric acids [8-11]. In our previous studies, we reported that artepillin $\mathrm{C}$, a major phenolic component of Brazilian propolis, suppressed tumor-induced angiogenesis [12].

Through our programs of revealing the constituents of the worldwide propolis, we have analyzed the components of a propolis collected in Okinawa, the southernmost prefecture of Japan [13-16]. It mainly contains prenylated flavonoids, which are called nymphaeols, analogs of naringenin, and/or eriodictyol (Figure 1), and the ethanol extracts of Okinawan propolis (EEOP) and the isolated prenylated flavonoids show strong antioxidant and antibacterial activities [13, 14]. In addition, they show cytotoxicity against some cancer cell lines as well as antimalarial activity [17]. Nymphaeols, the main prenylated flavonoids isolated from Okinawan propolis, have been reported to originate from Macaranga tanarius $[18,19]$. We have already revealed that the plant origin of Okinawan propolis is $M$. tanarius and that the major components of Okinawan propolis are nymphaeols-A (a) and -B (b) (Figure 1) [14].

In the present study, our aims were to investigate the in vivo antiangiogenic effects of EEOP and its two main prenylated flavonoids, nymphaeols-A and -B, by chorioallantoic membrane (CAM) assay using fertilized chicken eggs. Furthermore, we evaluated their modes of action of antiangiogenic effects by investigating the inhibition of tube formation, as well as changes in survival signals and apoptotic pathways using human umbilical vein endothelial cells (HUVECs).

\section{Materials and Methods}

2.1. Materials and Chemicals. Medium 199 was purchased from Sigma (St. Louis, MO, USA). Medium MCDB-104 was purchased from Nihon Pharmaceutical (Tokyo, Japan). Fetal bovine serum (FBS) was purchased from Moregate (Brisbane, Australia). Cellgen was obtained from Koken (Tokyo, Japan). Epidermal growth factor (EGF) was purchased from BD Biosciences (Bedford, MA, USA). Human basic Fibroblast Growth Factor (recombinant) was purchased from Wako Pure Chemicals Industries (Osaka, Japan).

Propolis used for this study was collected as a crude material by beekeepers of Aragaki bee farm, Naha, Okinawa, Japan, in June 2010. A voucher sample of the propolis (HSRCTU-BPC PR0002/2010) has been deposited at Bee Products Collection, Honeybee Science Research Center, Tamagawa University, Tokyo, Japan. Okinawan propolis collected from Okinawa, Japan, was extracted with ethanol by stirring overnight at room temperature. After extraction, the solvent was evaporated in vacuo to give EEOP. The nymphaeols used in the experiments were purified from the ethanol extracts of Okinawan propolis by column chromatography including HPLC as described previously [16]. The purity of each compound was $>98 \%$ using ${ }^{1} \mathrm{H}$ NMR spectrum.

2.2. Cell Culture. HUVECs were grown in HUVEC growth medium (MCDB-104 medium supplemented with $10 \mathrm{ng} / \mathrm{mL}$ EGF, $100 \mu \mathrm{g} / \mathrm{mL}$ heparin, $100 \mathrm{ng} / \mathrm{mL}$ endothelial cell growth factor, and 10\% FBS) as previously reported [20] and incubated at $37^{\circ} \mathrm{C}$ under a humidified $95 / 5 \%(\mathrm{v} / \mathrm{v})$ mixture of air and $\mathrm{CO}_{2}$. The cells were seeded on plates coated with $0.1 \%$ gelatin and allowed to grow to subconfluence before experimental treatments.

2.3. CAM Assay. CAM assay was performed as described previously [21]. Briefly, fertilized chicken eggs were incubated at $37^{\circ} \mathrm{C}$. On incubation day 3 , a small window was opened in the shell and $4 \mathrm{~mL}$ of albumen was removed. After incubation at $37^{\circ} \mathrm{C}$, the 5 -day-old CAM was treated with various doses of samples and incubated at $37^{\circ} \mathrm{C}$ for another 2 days. An appropriate volume of white emulsion was injected into CAM to clearly visualize the vascular network. Observation of the vascular networks was carried out to evaluate antiangiogenic activity. Retinoic acid (5 nmol/egg) was used as a positive control.

2.4. Tube Formation Assay. Capillary tube-like structures formed by HUVECs in collagen gel were prepared as previously described with slight modifications [20]. Collagen gels were made by Cellgen (type I collagen). $200 \mu \mathrm{L}$ of collagen solution (0.21\% in Medium-199) was poured into wells of a 24-well plate, and the plates were incubated at $37^{\circ} \mathrm{C}$ for $30 \mathrm{~min}$ to solidify gels. HUVECs $\left(6.0 \times 10^{4}\right.$ cells $\left./ \mathrm{cm}^{2}\right)$ in MCDB-104 medium with $0.5 \%$ FBS were seeded onto collagen-coated wells and left at $37^{\circ} \mathrm{C}$ in a $5 \% \mathrm{CO}_{2}$ incubator for $1 \mathrm{~h}$ to attach to the collagen gel. After removing the medium, $150 \mu \mathrm{L}$ of the collagen solution was overlaid and subjected to gelation as described above. Subsequently, $650 \mu \mathrm{L}$ of MCDB-104 with $0.5 \%$ FBS supplemented with $10 \mathrm{ng} / \mathrm{mL}$ bFGF, $8 \mathrm{nM} / \mathrm{mL}$ phorbol 12-myristate 13-acetate (PMA), together with various concentrations of samples, was added to the wells and incubated for up to $36 \mathrm{~h}$. The resulting web-like capillary structure was viewed under a microscope, and images were captured using an Olympus C-4040ZOOM digital camera (Olympus, Tokyo, Japan).

2.5. Western Blot Analysis. After experimental treatment with various doses of samples, cells embedded $3 \mathrm{D}$ in collagen gel were treated with SDS sample buffer $(50 \mathrm{mM}$ Tris- $\mathrm{HCl}$ (pH 6.8), 2\% SDS, 5.88\% 2-mercaptoethanol, 10\% glycerin, $1 \mathrm{mM} \beta$-glycerophosphate, $2.5 \mathrm{mM}$ sodium pyrophosphate, $1 \times$ phosphatase inhibitor cocktail $1,1 \times$ phosphatase inhibitor cocktail 2 , and $1 \times$ protease inhibitor cocktail 1 ) and boiled for $10 \mathrm{~min}$. Each sample was electrophoresed in 6-12\% SDSpolyacrylamide gels and then transferred to a Hybond-ECL nitrocellulose membrane (GE Healthcare, Buckinghamshire, UK). Immunoreactive protein bands were visualized using the ECL plus detection system with an ECL Minicamera (GE Healthcare). Results were obtained from three independent experiments.

2.6. Caspase Inhibition by z-VAD-fmk. HUVECs in MCDB104 with $0.5 \%$ FBS supplemented with $10 \mathrm{ng} / \mathrm{mL}$ bFGF, $8 \mathrm{nM} / \mathrm{mL}$ PMA on 96-well plates were treated with both 1.56$6.25 \mu \mathrm{g} / \mathrm{mL}$ nymphaeol-A and $10 \mu \mathrm{M} \mathrm{z}$-VAD-fmk (Promega, WI, USA), an irreversible pan-caspase inhibitor, for $12 \mathrm{~h}$. Caspase-3/7 activity was examined by a Caspase-Glo Assay 
<smiles>CC(C)=CCC/C(C)=C/Cc1c(O)cc2c(c1O)C(=O)C[C@@H](c1ccc(O)c(O)c1)O2</smiles>

(a)<smiles>CC(C)=CCC/C(C)=C/Cc1cc([C@H]2CC(=O)c3c(O)cc(O)cc3O2)cc(O)c1O</smiles>

(c)<smiles>CC(C)=CCC/C(C)=C/Cc1c([C@H]2CC(=O)c3c(O)cc(O)cc3O2)ccc(O)c1O</smiles>

(b)<smiles>CC(C)=CCC/C(C)=C/Cc1cc([C@H]2CC(=O)c3c(O)cc(O)cc3O2)ccc1O</smiles>

(d)<smiles>CC(C)=CCC/C(C)=C/Cc1c([C@H]2CC(=O)c3c(cc(O)c(CC=C(C)C)c3O)O2)ccc(O)c1O</smiles>

(e)<smiles>O=C1C[C@H](c2ccc(O)cc2)Oc2cc(O)cc(O)c21</smiles>

Naringenin

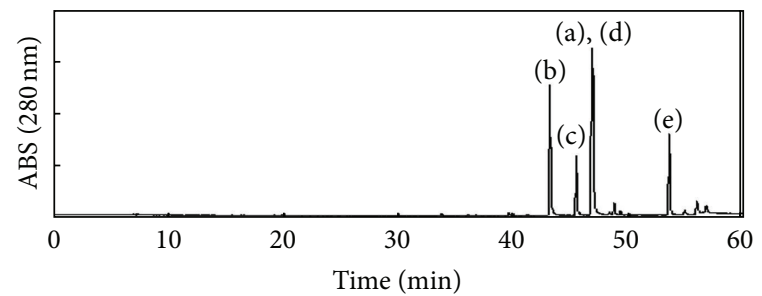<smiles>CCOC(C)(C)OCC</smiles>

FIGURE 1: Structures of the main components isolated from Okinawan propolis and HPLC profile of EEOP. (a) Nymphaeol-A; (b) nymphaeolB; (c) isonymphaeol-B; (d) 3'-geranyl-naringenin; (e) nymphaeol-C; naringenin, and eriodictyol. HPLC conditions: column, Capcell Pak UG120 C18 column $(250 \times 4.6 \mathrm{~mm}$ i.d.; Shiseido, Tokyo, Japan); flow rate, $1.0 \mathrm{~mL} / \mathrm{min}$; detection, $280 \mathrm{~nm}$; solvent, (A) water with $0.1 \%$ trifluoroacetic acid (B) acetonitrile with $0.1 \%$ trifluoroacetic acid (B); gradient, $10-100 \%$ (B) in $60 \mathrm{~min}$.

(Promega) according to the manufacturer's protocol. Luminescence was measured using a Flex Station II system (Molecular Devices, Inc., CA, USA).

2.7. ERK1/2 Activation by Angiotensin II. HUVECs in MCDB104 with $10 \%$ FBS on 96-well plates were pretreated with
$1 \mu \mathrm{M}$ angiotensin II (Sigma) for $2 \mathrm{~h}$. Pretreated HUVECs were incubated with $3.13 \mu \mathrm{g} / \mathrm{mL}$ nymphaeol-A. Caspase-3/7 activity was examined by a Caspase-Glo Assay (Promega) according to the manufacturer's protocol. Luminescence was measured using a Flex Station II system (Molecular Devices, Inc.). 


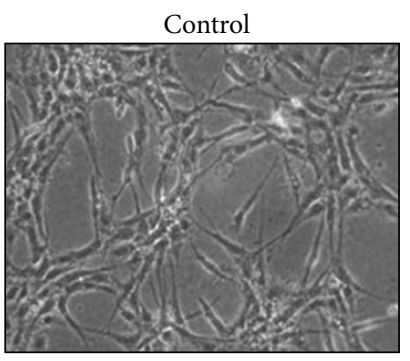

$24 \mathrm{~h}$
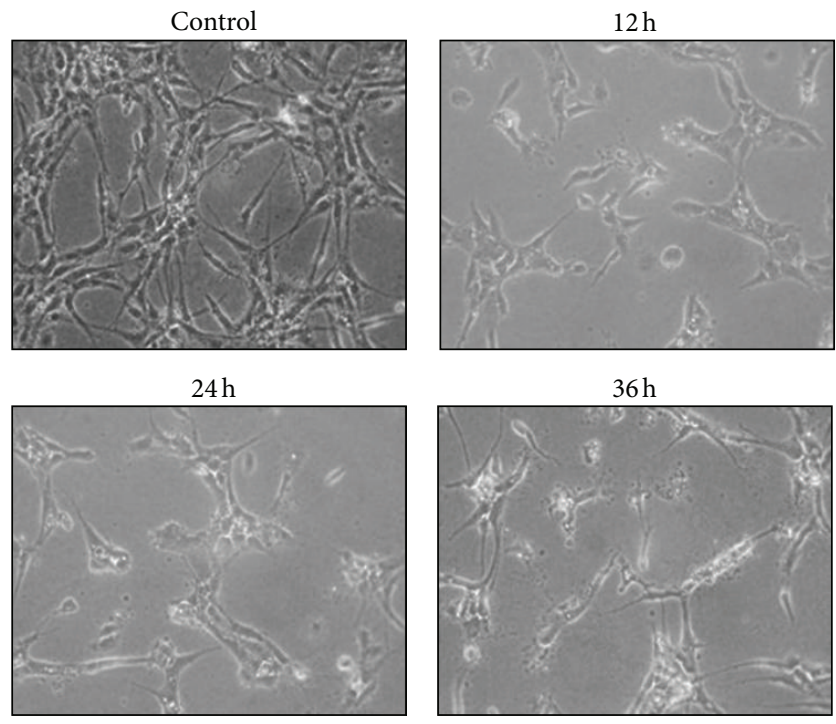

$36 \mathrm{~h}$

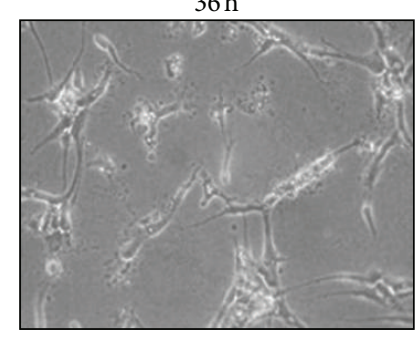

FIGURE 2: EEOP inhibits tube formation in HUVECs. HUVECs were sandwiched between two layers of collagen gel and induced to form blood-vessel-like tubes. HUVECs were treated with $3.13 \mu \mathrm{g} / \mathrm{mL}$ EEOP for the indicated time periods.

2.8. Statistical Analysis. All data was expressed as means \pm SEM of at least three independent experiments. Comparisons between control and treatments were performed using Student's unpaired $t$-test $\left({ }^{*} P<0.05\right)$.

\section{Results}

3.1. Antiangiogenic Activity of EEOP In Vitro and In Vivo. We first examined the effects of ethanol extracts of Okinawan propolis (EEOP) in tube formation assay as an in vitro model and CAM assay as an in vivo model.

The tube formation assay was carried out using HUVECs and the extent of capillary network formation was evaluated. Regarding the CAM assay, the fertilized chicken egg model is a well-known animal model in biological and pharmaceutical research in terms of simplicity and low cost. Because CAMs have a very dense capillary network, CAM assays are commonly used to study in vivo angiogenesis and its inhibition in response to different compounds. In the CAM assay, the antiangiogenic activities of samples were judged on day 7 .

As shown in Figures 2 and 3, EEOP inhibited angiogenesis in both in vitro and in vivo models. EEOP inhibited the formation of capillary networks by HUVECs at $3.13 \mu \mathrm{g} / \mathrm{mL}$, time-dependently, and also suppressed embryonic angiogenesis at 12.5 and $25 \mu \mathrm{g} / \mathrm{egg}$.

3.2. Antiangiogenic Activity In Vitro of Nymphaeols and Their Derivatives Isolated from EEOP. EEOP showed antiangiogenic activity in tube formation and CAM assays. To confirm the active compounds, five prenylated flavonoids were isolated and purified by repeated column chromatographies.
Figure 1 shows the chemical structures isolated from EEOP and the HPLC chromatogram of EEOP.

These compounds were tested for antiangiogenic effects in tube formation assay (Figure 4). Among them, nymphaeolA, the main component of EEOP, showed the strongest activity compared with that of other prenylated flavonoids. We also evaluated the anti-tube-forming activity of naringenin and eriodictyol, which possess the same main skeleton as these prenylated derivatives, but neither showed any detectable activity at $25 \mu \mathrm{g} / \mathrm{mL}$ (data not shown). These results indicate that it is important to have a geranyl moiety at the C-6 position for antitube-formation activity.

3.3. Antiangiogenic Activity In Vivo of Nymphaeols-A and $-B$. We decided to evaluate in vivo antiangiogenic activities of nymphaeols-A and/or - $\mathrm{B}$ because they were the main components of EEOP and could be the cause of the antiangiogenic activity of EEOP using the CAM assay. As shown in Figure 5, nymphaeol-A inhibited embryonic angiogenesis at $12.5 \mu \mathrm{g} / \mathrm{egg}$. Nymphaeol-B also showed antiangiogenic activity, but the activity of nymphaeol-B was weaker than that of nymphaeol-A (Figure 6). This in vivo result was consistent with the findings in the in vitro tube-forming model. Thus, the importance of having a geranyl moiety at the C-6 position for antiangiogenic activity has been shown both in vivo and in vitro.

3.4. Caspase Activation and Apoptosis Induction by Nymphaeol-A. To examine whether apoptosis was involved in antiangiogenic effects of nymphaeol-A, tube-forming HUVECs were treated with nymphaeol-A at various concentrations. After treatment for different time periods, activation of caspase-3, one of the effector caspases of apoptosis, was evaluated by western blotting analysis.

As shown in Figure 7, treatment with nymphaeol-A significantly increased the level of cleaved caspase-3, the active form, in a time- and a concentration-dependent manner, and decreased the level of procaspase-3. To identify the signal cascade that leads to caspase- 3 activation, we analyzed the activation of caspase- 9 by western blotting. The signal for procaspase- 9 was decreased after treatment with nymphaeol-A in a time- and concentration-dependent manner (Figure 7). PARP is a $116-\mathrm{kDa}$ nuclear poly (ADPribose) polymerase known to be a molecular marker of apoptosis. The band for cleaved PARP was detected after treating cells with nymphaeol-A, also in a time- and concentrationdependent manner (Figure 7). These results confirmed that nymphaeol-A induces apoptosis in tube-forming HUVECs.

We focused on the caspase-dependent apoptosis induced by nymphaeol-A. We examined the contribution of nymphaeol-A to caspase-dependent apoptosis by simultaneous addition of the substance and pan-caspase inhibitor $\mathrm{z}$ VAD-fmk to tube-forming HUVECs. Simultaneous addition of nymphaeol-A and z-VAD-fmk $(10 \mu \mathrm{M})$ completely blocked nymphaeol-A-induced apoptosis of tube-forming HUVECs (Figure 8). This result strongly suggested that nymphaeolA-induced cell death in tube-forming HUVECs occurs via caspase-dependent apoptosis. 


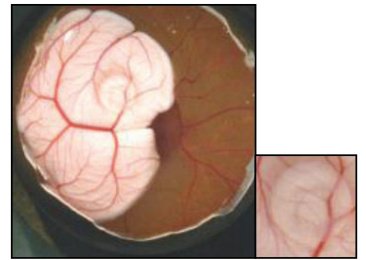

Control (DMSO)

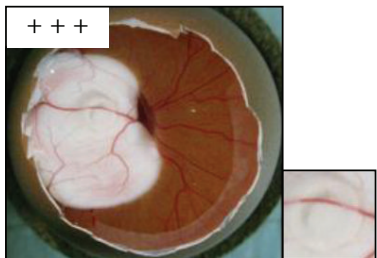

Positive control (retinoic acid $5 \mathrm{nmol} / \mathrm{egg}$ )

(b)

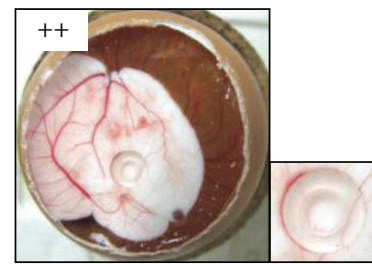

$12.5 \mu \mathrm{g} / \mathrm{egg}$

(c)

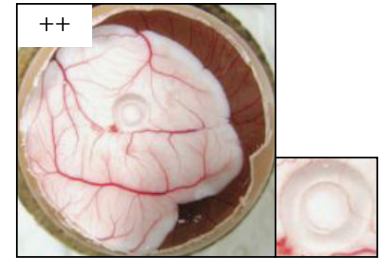

$25 \mu \mathrm{g} / \mathrm{egg}$

(d)

Figure 3: EEOP inhibits angiogenesis in vivo. EEOP showed antiangiogenic effects in CAM assay. (a) Control; (b) 5 nmol/egg Retinoic acid; (c) $12.5 \mu \mathrm{g} / \mathrm{egg}$ EEOP; (d) $25 \mu \mathrm{g} / \mathrm{egg}$ EEOP.
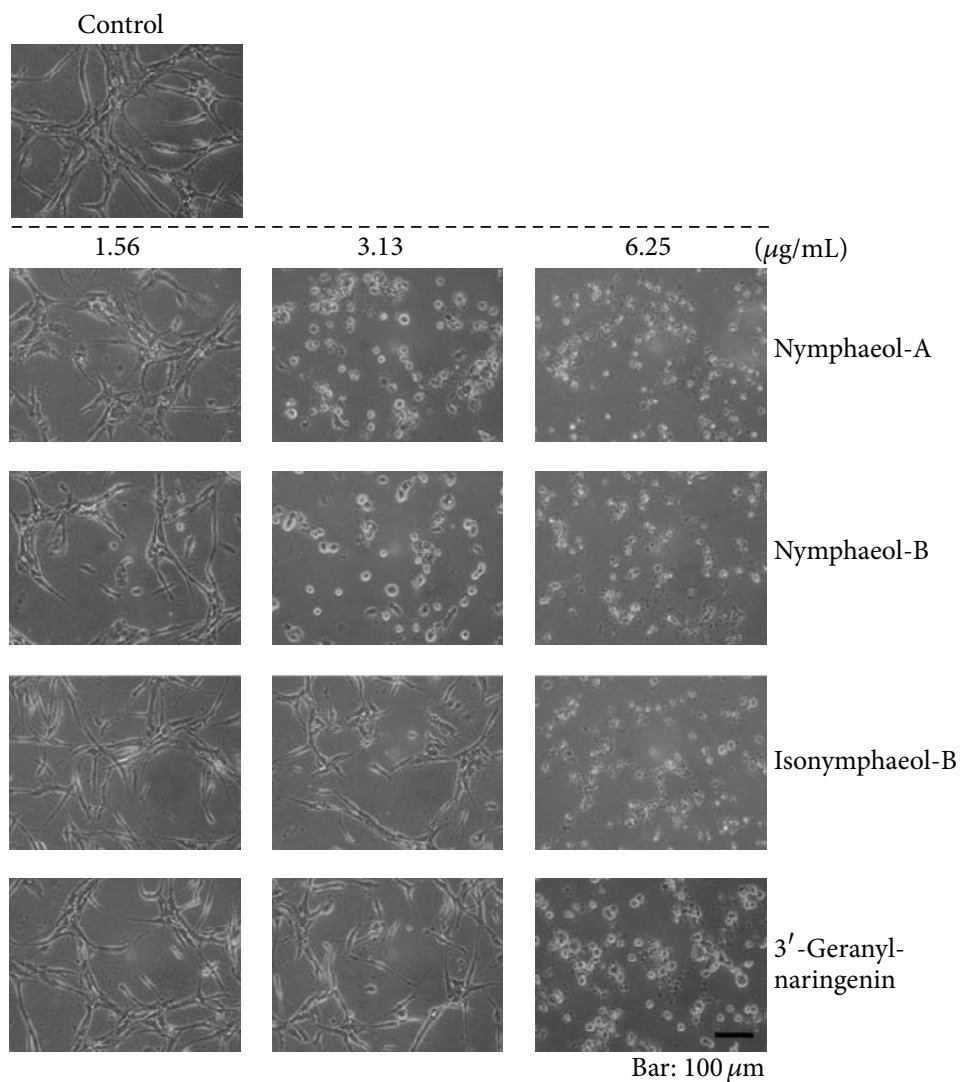

FIGURE 4: Nymphaeol derivatives inhibit angiogenesis in vitro. HUVECs were sandwiched between two layers of collagen gel and induced to form blood-vessel-like tubes. HUVECs were treated with the indicated concentrations of each compound for $36 \mathrm{~h}$.

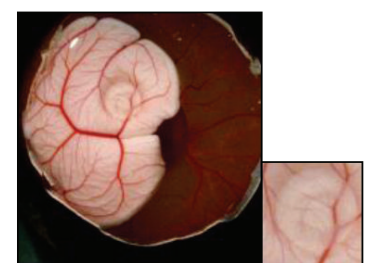

Control (DMSO)

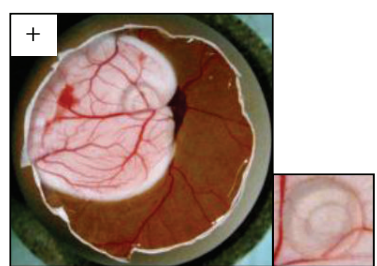

$12.5 \mu \mathrm{g} / \mathrm{egg}$

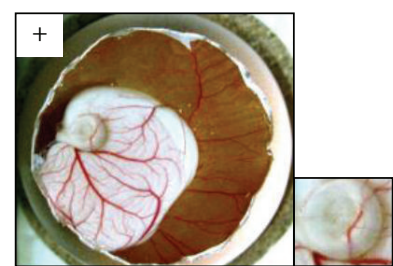

$25 \mu \mathrm{g} / \mathrm{egg}$

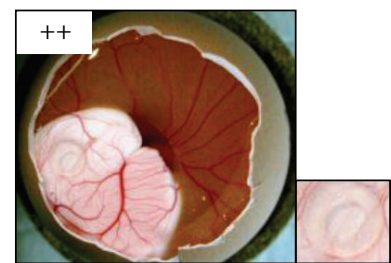

$50 \mu \mathrm{g} / \mathrm{egg}$

(a)

(b)

(c)

(d)

Figure 5: Nymphaeol-A inhibits angiogenesis in vivo. Nymphaeol-A showed strong antiangiogenic effects in CAM assay. (a) Control; (b) $12.5 \mu \mathrm{g} /$ egg nymphaeol-A; (c) $25 \mu \mathrm{g} /$ egg nymphaeol-A; (d) $50 \mu \mathrm{g} /$ egg nymphaeol-A. 


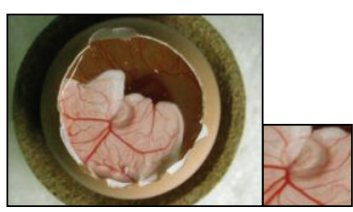

Control

(DMSO)

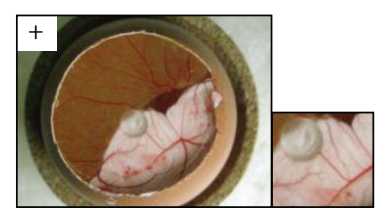

$12.5 \mu \mathrm{g} / \mathrm{egg}$

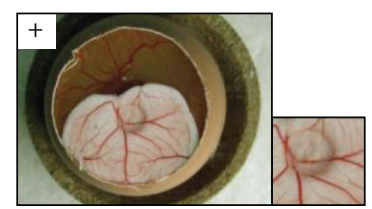

$25 \mu \mathrm{g} / \mathrm{egg}$

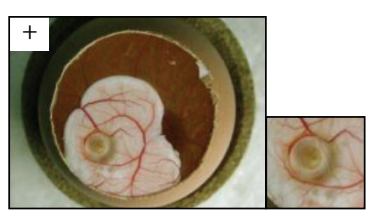

$50 \mu \mathrm{g} / \mathrm{egg}$

(a)

(b)

(c)

(d)

FIgure 6: Nymphaeol-B inhibits angiogenesis in vivo. Nymphaeol-B showed an antiangiogenic effect in CAM assay. (a) Control; (b) $12.5 \mu \mathrm{g} /$ egg nymphaeol-B; (c) $25 \mu \mathrm{g} /$ egg nymphaeol-B; (d) $50 \mu \mathrm{g} /$ egg nymphaeol-B.

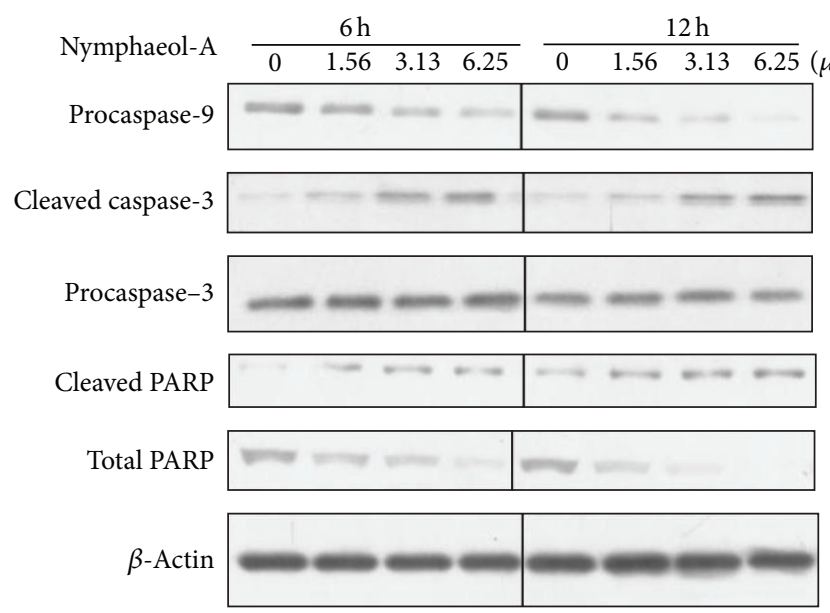

Figure 7: Nymphaeol-A activates caspases in tube-forming HUVECs. HUVECs were treated with $0.4 \%$ DMSO $(0 \mu \mathrm{g} / \mathrm{mL})$ or nymphaeol-A at the indicated concentrations for $6 \mathrm{~h}$ and $12 \mathrm{~h}$, respectively. Changes in the levels of caspase- 9 , caspase-3, and PARP were analyzed by western blotting. Each experiment was repeated at least three times and representative data are shown.

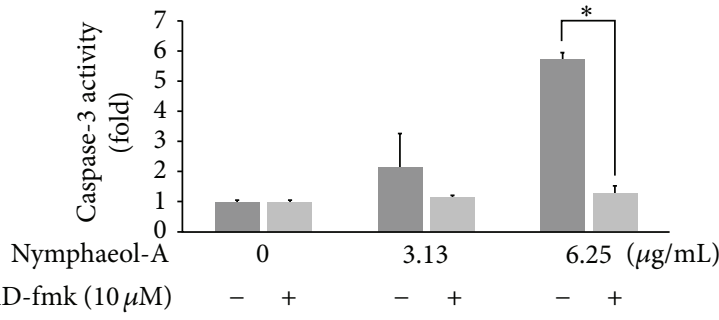

FIGURE 8: z-VAD-fmk reverses apoptosis induction by nymphaeolA. HUVECs were treated with nymphaeol-A at the indicated concentrations and $10 \mu \mathrm{M} z$-VAD-fmk, a pan-caspase inhibitor, for $12 \mathrm{~h}$. Caspase-3/7 activity was measured using the Caspase-Glo Assay Kit by luminescence assays as described in the text. ${ }^{*} P<0.05$, as compared with the control group.

3.5. Inactivation of Survival Signals by Nymphaeol-A. We further analyzed how survival signals were affected by nymphaeol-A using western blotting analysis. Mitogenactivated protein kinase/ERK kinase 1/2 (MEK1/2) is one of the major survival signals in mammalian cells and is known to directly phosphorylate extracellular signal-regulated kinase 1/2 (ERK1/2). Treatment of tube-forming HUVECs with nymphaeol-A $(1.56 \mu \mathrm{g} / \mathrm{mL})$ markedly decreased the phosphorylation of MEK1/2. Subsequently, ERK1/2, which acts downstream of MEK1/2, was also inactivated by nymphaeol-A without any changes in total ERK expression (Figure 9). These observations showed that nymphaeol-A is involved in inhibiting MEK1/2 activation and subsequently inactivates ERK1/2, a cell survival signal in tube-forming HUVECs.

To confirm this effect of nymphaeol-A on the MAPK cascade, we used angiotensin II. Angiotensin II, a peptide hormone that causes vasoconstriction and a subsequent increase in blood pressure, is known to activate MAPK and to phosphorylate ERK1/2 in endothelial cells [22]. Treatment of HUVECs with $3.13 \mu \mathrm{g} / \mathrm{mL}$ of nymphaeol-A for $3 \mathrm{~h}$ induced caspase- 3 activation. Angiotensin II pretreatment, which caused activation of ERK1/2, completely blocked this activation of caspase-3 (Figure 10). This result indicates that angiotensin II inhibits nymphaeol-A-induced apoptosis.

\section{Discussion}

In this study, through our screening program to search for bioactive components with antiangiogenic effects from propolis, we found that the ethanol extracts of Okinawan propolis (EEOP) showed strong antiangiogenic activity in vitro and in vivo. To find the active components with such 

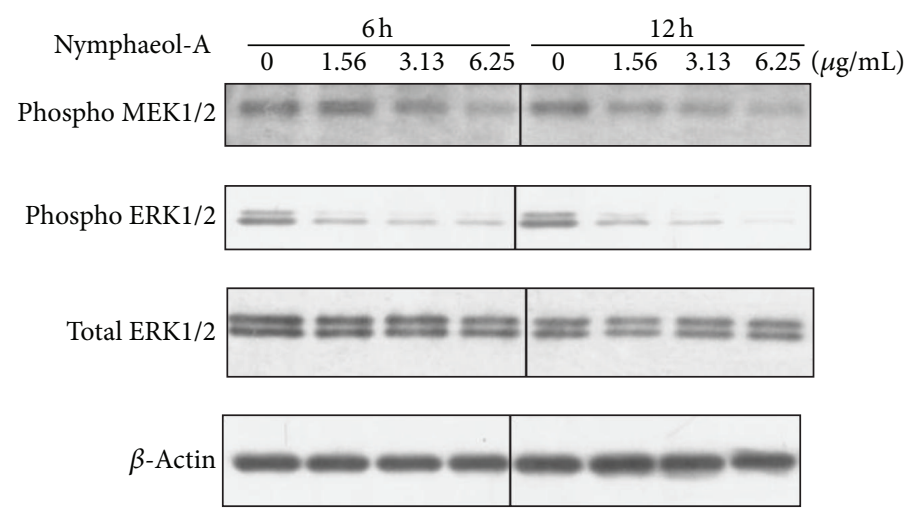

FIgURE 9: Nymphaeol-A inactivates MEK1/2 and ERK1/2 phosphorylation. Tube-forming HUVECs were treated with $0.4 \%$ DMSO $(0 \mu \mathrm{g} / \mathrm{mL})$ or nymphaeol-A at the indicated concentrations for $6 \mathrm{~h}$ and $12 \mathrm{~h}$, respectively. Changes in the phosphorylation state of ERK1/2 at Thr202/Tyr204 and MEK1/2 at Ser221 were analyzed by western blotting. Each experiment was repeated at least three times and representative data are shown.

antiangiogenic effects, five prenylflavonoids analogs were isolated from EEOP, and nymphaeol-A was investigated for their modes of action of antiangiogenic effect.

We first confirmed that EEOP showed antiangiogenic effects in tube formation assay in vitro using tube-forming HUVECs and chorioallantoic membrane (CAM) assay in vivo using fertilized chicken eggs. With isolated main components from EEOP, nymphaeols-A and -B had a strong anti-tube-forming activity in vitro. Although isonymphaeol$\mathrm{B}, 3^{\prime}$-geranyl-naringenin, eriodictyol, and naringenin were shown to inhibit angiogenesis, the effective concentration was higher than that of nymphaeols. In general, it was indicated that the existence of the geranyl moiety was important to express bioactivity $[23,24]$. Two of the main components of EEOP, nymphaeols-A and -B, both of which have a prenyl group, showed the strongest anti-tube-forming effect in vitro among identified compounds from EEOP. There are some reports which show that remarkable difference of bioactivity arises depending upon the substitution sites of prenyl groups. Particulaly, the existence of prenyl group at C-6 of A ring and catechol structure at $\mathrm{B}$ ring of flavonoids was reported to be important for their biological activities such as antioxidative, antifungal, and antimelanogenesis activites [25-28]. Our results corresponded partly with these studies. Furthermore, nymphaeol-A was also found to inhibit angiogenesis in vivo. Nymphaeol-B also had antiangiogenic activity in vivo, but it was weaker than nymphaeol-A.

Based on these results, it was concluded that nymphaeolA had antiangiogenic activities in vitro and in vivo and could be the primary active component of Okinawan propolis. In addition, these results indicate that propolis from Okinawa might have a tumor-suppressing effect through inhibition of angiogenesis.

We further examined the mechanism of angiogenesis inhibition through nymphaeol-A at the molecular level. Caspase-9, an intrinsic initiator caspase, was activated by nymphaeol-A. Subsequently, caspase-3, an effector caspase, was activated. Treatment with pan-caspase inhibitor z-VADfmk was shown to reverse nymphaeol-A-induced caspase-3 activation (Figure 8). These results indicated that nymphaeolA induces apoptosis in tube-forming HUVECs through the activation of caspase signaling (Figure 7).

MAPK signaling plays important roles in the regulation of angiogenesis, such as stimulation of endothelial cell proliferation, migration, and tube formation [29]. Among MAPK family members, ERKs have been reported to have essential roles in endothelial cell survival and cell migration $[30,31]$. Inactivation of these survival signals is known to trigger apoptosis through activation of caspase pathways in endothelial cells [32]. As shown in Figure 9, changes in the level of phosphorylation of MEK1/2 and ERK1/2 were induced in a time- and concentration-dependent manner by nymphaeol-A in HUVECs. Furthermore, Kunimasa et al. revealed that inhibition of MEK1/2 by U0126, MEK1/2 inhibitor, induced apoptosis in HUVECs [32]. These results suggested that caspase activity is regulated by MEK1/2 and ERK1/2 activation in HUVECs. Therefore, our results imply a specific involvement of ERK1/2 and MEK1/2 inactivation in nymphaeol-A-induced apoptosis and its inhibition of angiogenesis. There are some reports that angiotensin II activates the family of mitogen-activated protein kinases (MAPK), including ERK, JNK, and p38 MAPK $[33,34]$. Guo et al. observed an effect of angiotensin II on MAPKs in HUVECs and showed that angiotensin II induced phosphorylation of ERK [22]. Pretreatment of HUVECs with angiotensin II completely inhibited nymphaeol-A-induced caspase- 3 activation (Figure 10). This result showed that nymphaeol-A acts through the ERK cascade (MEK1/2 and ERK1/2) to subsequently induce apoptosis.

The cell viability of HUVECs in tube formation medium with $5 \mu \mathrm{g} / \mathrm{mL}$ of nymphaeol-A was $<10 \%$; however, in growth medium, it was around $60 \%$ (data not shown). According to this result, nymphaeol-A may affect tube-forming HUVECs, rather than proliferation-phase HUVECs, by activating the survival signaling. We need to further investigate how nymphaeol-A affects other signaling pathways and induces apoptosis in tube-forming HUVECs at the molecular level. We showed that EEOP and nymphaeol-A inhibit angiogenesis 


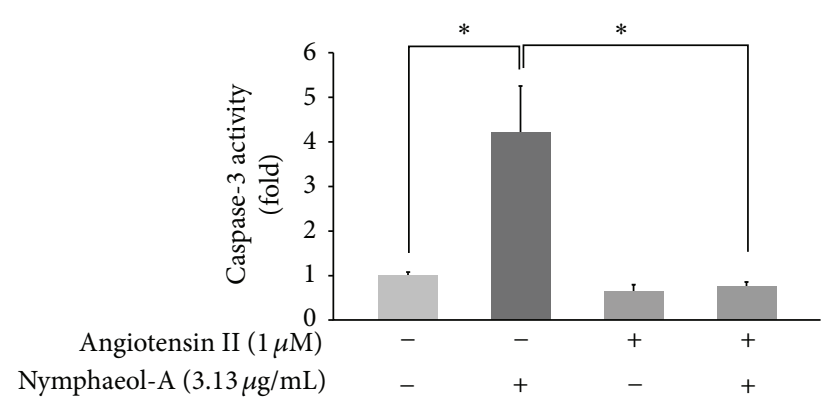

FIGURE 10: Angiotensin II reverses inactivation of ERK1/2 by nymphaeol-A. HUVECs were pretreated with $1 \mu \mathrm{M}$ angiotensin II, an ERK1/2 activator, for $3 \mathrm{~h}$. Pretreated cells were incubated with nymphaeol-A at the indicated concentrations for $3 \mathrm{~h}$. Caspase3/7 activity was measured using the Caspase-Glo Assay Kit by luminescence assays as described in the text. ${ }^{*} P<0.05$, as compared with the control group.

in vitro and in vivo. Based on these results, nymphaeol-A may represent a new dietary-derived antiangiogenic compound. In addition, these results strongly support the possibility that we can prevent cancer or angiogenesis-related diseases by daily intake of Okinawan propolis which contains nymphaeol-A.

\section{Conflict of Interests}

The authors declare that they have no conflict of interests.

\section{Authors' Contribution}

Ikumi Tsuchiya and Takahiro Hosoya contributed equally to this work.

\section{Acknowledgment}

This work was supported in part by JSPS KAKENHI Grant nos. 21500782 and 23580180.

\section{References}

[1] J. Folkman, "Tumor angiogenesis: therapeutic implications," New England Journal of Medicine, vol. 285, no. 21, pp. 1182-1186, 1971.

[2] S. Kumazawa, T. Hamasaka, and T. Nakayama, "Antioxidant activity of propolis of various geographic origins," Food Chemistry, vol. 84, no. 3, pp. 329-339, 2004.

[3] E. L. Ghisalberti, "Propolis: a review, Bee World, vol. 60, no. 2, pp. 59-84, 1979.

[4] A. Kujumgiev, I. Tsvetkova, Y. Serkedjieva, V. Bankova, R. Christov, and S. Popov, "Antibacterial, antifungal and antiviral activity of propolis of different geographic origin," Journal of Ethnopharmacology, vol. 64, no. 3, pp. 235-240, 1999.

[5] M. Amoros, E. Lurton, J. Boustie, L. Girre, F. Sauvager, and M. Cormier, "Comparison of the anti-herpes simplex virus activities of propolis and 3-methyl-but-2-enyl caffeate," Journal of Natural Products, vol. 57, no. 5, pp. 644-647, 1994.
[6] J. M. Sforcin, "Propolis and the immune system: a review," Journal of Ethnopharmacology, vol. 113, no. 1, pp. 1-14, 2007.

[7] S. V. McLennan, J. Bonner, S. Milne et al., "The anti-inflammatory agent Propolis improves wound healing in a rodent model of experimental diabetes," Wound Repair and Regeneration, vol. 16, no. 5, pp. 706-713, 2008.

[8] T. Kimoto, M. Aga, K. Hino et al., "Apoptosis of human leukemia cells induced by Artepillin C, an active ingredient of Brazilian propolis," Anticancer Research, vol. 21, no. 1 A, pp. 221-228, 2001.

[9] M. C. Marcucci, "Propolis: chemical composition, biological properties and therapeutic activity," Apidologie, vol. 26, no. 2, pp. 83-99, 1995.

[10] M. Velikova, V. Bankova, K. Sorkun, S. Popov, and A. Kujumgiev, "Chemical composition and biological activity of propolis from Turkish and Bulgarian origin," Mellifera, vol. 1, no. 1, pp. 57-59, 2001.

[11] T. Hamasaka, S. Kumazawa, T. Fujimoto, and T. Nakayama, "Antioxidant activity and constituents of propolis collected in various areas of Japan," Food Science and Technology Research, vol. 10, no. 1, pp. 86-92, 2004.

[12] M. R. Ahn, K. Kunimasa, T. Ohta et al., "Suppression of tumorinduced angiogenesis by Brazilian propolis: major component artepillin C inhibits in vitro tube formation and endothelial cell proliferation," Cancer Letters, vol. 252, no. 2, pp. 235-243, 2007.

[13] S. Kumazawa, R. Ueda, T. Hamasaka, S. Fukumoto, T. Fujimoto, and T. Nakayama, "Antioxidant prenylated flavonoids from propolis collected in Okinawa, Japan," Journal of Agricultural and Food Chemistry, vol. 55, no. 19, pp. 7722-7725, 2007.

[14] S. Kumazawa and S. Fukumoto, "Macaranga tanarius, the plant origin of Okinawan propolis," Honeybee Science, vol. 28, no. 1, pp. 1-6, 2010 (Japanese).

[15] S. Kumazawa, J. Nakamura, M. Murase, M. Miyagawa, M. R. Ahn, and S. Fukumoto, "Plant origin of Okinawan propolis: honeybee behavior observation and phytochemical analysis," Naturwissenschaften, vol. 95, no. 8, pp. 781-786, 2008.

[16] S. Kumazawa, H. Goto, T. Hamasaka, S. Fukumoto, T. Fujimoto, and T. Nakayama, "A new prenylated flavonoid from propolis collected in Okinawa, Japan," Bioscience, Biotechnology and Biochemistry, vol. 68, no. 1, pp. 260-262, 2004.

[17] C. N. Chen, C. L. Wu, H. S. Shy, and J. K. Lin, "Cytotoxic prenylflavanones from Taiwanese propolis," Journal of Natural Products, vol. 66, no. 4, pp. 503-506, 2003.

[18] S. Phommart, P. Sutthivaiyakit, N. Chimnoi, S. Ruchirawat, and S. Sutthivaiyakit, "Constituents of the leaves of Macaranga tanarius," Journal of Natural Products, vol. 68, no. 6, pp. 927-930, 2005.

[19] O. Guhling, C. Kinzler, M. Dreyer, G. Bringmann, and R. Jetter, "Surface composition of myrmecophilic plants: cuticular wax and glandular trichomes on leaves of Macaranga tanarius," Journal of Chemical Ecology, vol. 31, no. 10, pp. 2323-2341, 2005.

[20] T. Kondo, T. Ohta, K. Igura, Y. Hara, and K. Kaji, “Tea catechins inhibit angiogenesis in vitro, measured by human endothelial cell growth, migration and tube formation, through inhibition of VEGF receptor binding," Cancer Letters, vol. 180, no. 2, pp. 139-144, 2002.

[21] S. Nakayama, Y. Uto, K. Tanimoto et al., "TX-2152: a conformationally rigid and electron-rich diyne analogue of FTY720 with in vivo antiangiogenic activity," Bioorganic and Medicinal Chemistry, vol. 16, no. 16, pp. 7705-7714, 2008.

[22] R. W. Guo, L. X. Yang, M. Q. Li, B. Liu, and X. M. Wang, "Angiotensin II induces NF- $\kappa$ B activation in HUVEC via the 
p38MAPK pathway," Peptides, vol. 27, no. 12, pp. 3269-3275, 2006.

[23] Y. Shirataki, N. Motohashi, S. Tani et al., "In vitro biological activity of prenylflavanones," Anticancer Research, vol. 21, no. 1 A, pp. 275-280, 2001.

[24] R. Mukai, H. Horikawa, Y. Fujikura et al., "Prevention of disuse muscle atrophy by dietary ingestion of 8 -prenylnaringenin in denervated mice," PLoS One, vol. 7, no. 9, 2012.

[25] E. T. Arung, K. Shimizu, and R. Kondo, "Structure-activity relationship of prenyl-substituted polyphenols from Artocarpus heterophyllus as inhibitors of melanin biosynthesis in cultured melanoma cells," Chemistry and Biodiversity, vol. 4, no. 9, pp. 2166-2171, 2007.

[26] Y. Zhang, X. L. Li, X. S. Yao, and M. S. Wong, "Osteogenic activities of genistein derivatives were influenced by the presence of prenyl group at ring A," Archives of Pharmacal Research, vol. 31, no. 12, pp. 1534-1539, 2008.

[27] G. Grünz, K. Haas, S. Soukup et al., "Structural features and bioavailability of four flavonoids and their implications for lifespan-extending and antioxidant actions in C. elegans," Mechanisms of Ageing and Development, vol. 133, no. 1, pp. 1-10, 2012.

[28] L. De Martino, T. Mencherini, E. Mancini, R. P. Aquino, L. F. De Almeida, and V. De Feo, "In vitro phytotoxicity and antioxidant activity of selected flavonoids," International Journal of Molecular Sciences, vol. 13, no. 5, pp. 5406-5419, 2012.

[29] R. L. Klemke, S. Cai, A. L. Giannini, P. J. Gallagher, P. De Lanerolle, and D. A. Cheresh, "Regulation of cell motility by mitogen-activated protein kinase," Journal of Cell Biology, vol. 137, no. 2, pp. 481-492, 1997.

[30] R. Seger and E. G. Krebs, “The MAPK signaling cascade," FASEB Journal, vol. 9, no. 9, pp. 726-735, 1995.

[31] R. Eguchi, A. Suzuki, S. Miyakaze, K. Kaji, and T. Ohta, "Hypoxia induces apoptosis of HUVECs in an in vitro capillary model by activating proapoptotic signal p38 through suppression of ERK1/2," Cellular Signalling, vol. 19, no. 6, pp. 1121-1131, 2007.

[32] K. Kunimasa, M.-R. Ahn, T. Kobayashi et al., "Brazilian propolis suppresses angiogenesis by inducing apoptosis in tube-forming endothelial cells through inactivation of survival signal ERK1/2," Evidence-Based Complementary and Alternative Medicine, vol. 2010, Article ID 870753, 8 pages, 2010.

[33] D. Daniels, D. K. Yee, L. F. Faulconbridge, and S. J. Fluharty, "Divergent behavioral roles of angiotensin receptor intracellular signaling cascades," Endocrinology, vol. 146, no. 12, pp. 5552$5560,2005$.

[34] Y. Zhao, J. Liu, L. Li, L. Liu, and L. Wu, "Role of Ras/ PKCzeta/MEK/ERK1/2 signaling pathway in angiotensin IIinduced vascular smooth muscle cell proliferation," Regulatory Peptides, vol. 128, no. 1, pp. 43-50, 2005. 


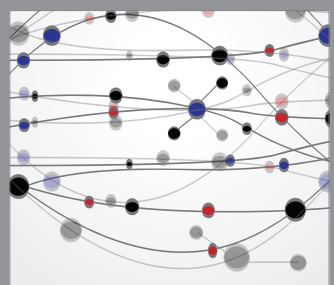

The Scientific World Journal
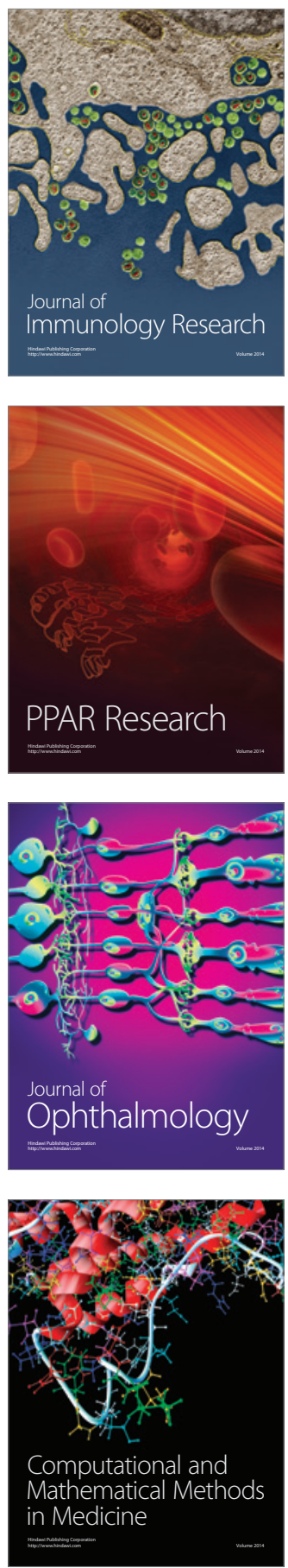

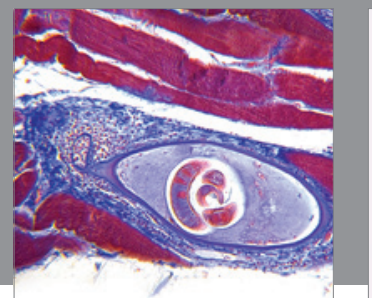

Gastroenterology

Research and Practice
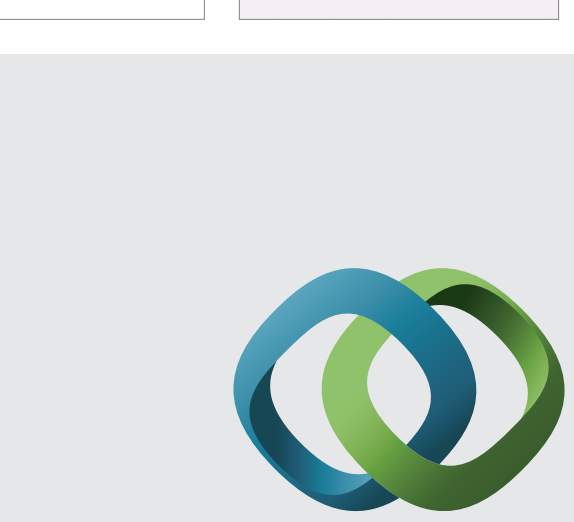

\section{Hindawi}

Submit your manuscripts at

http://www.hindawi.com
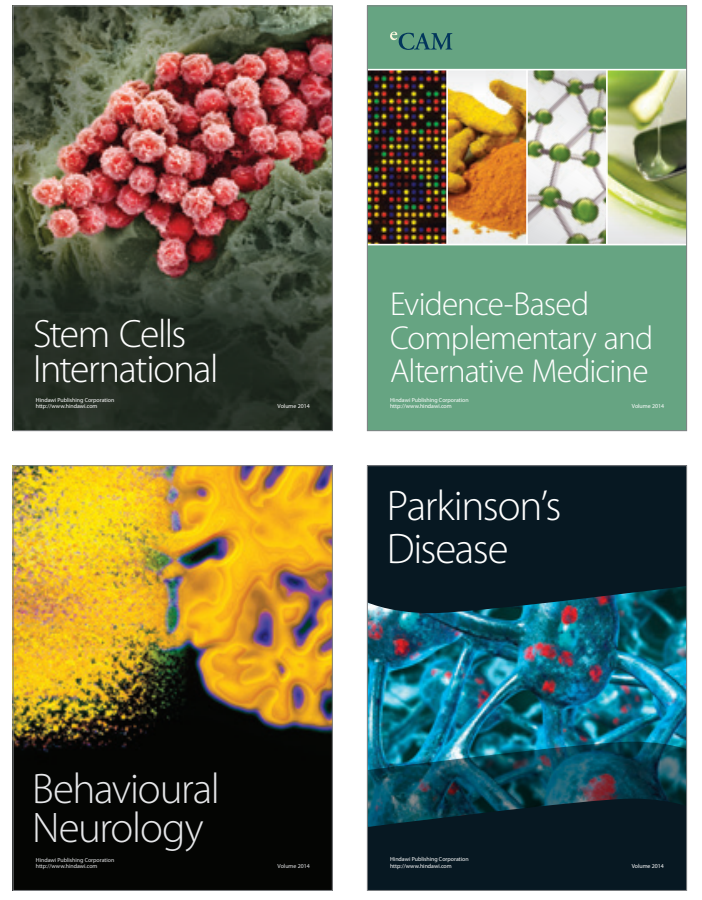
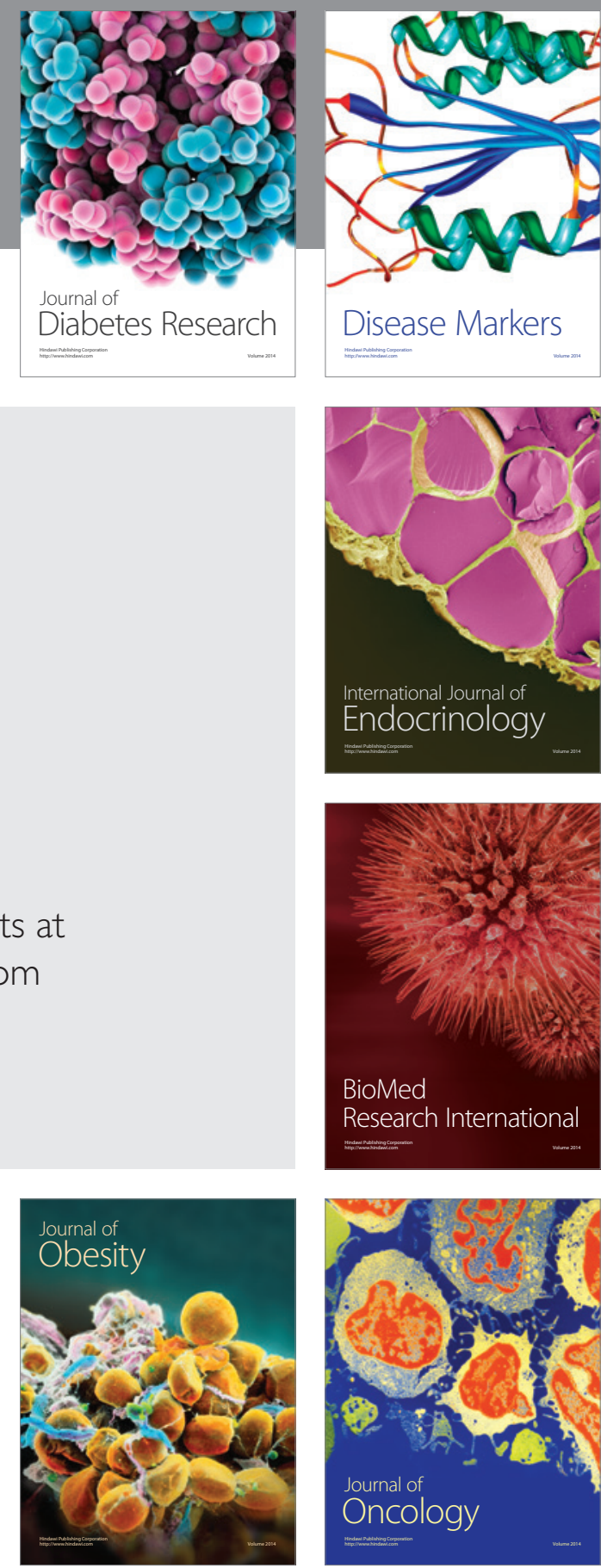

Disease Markers
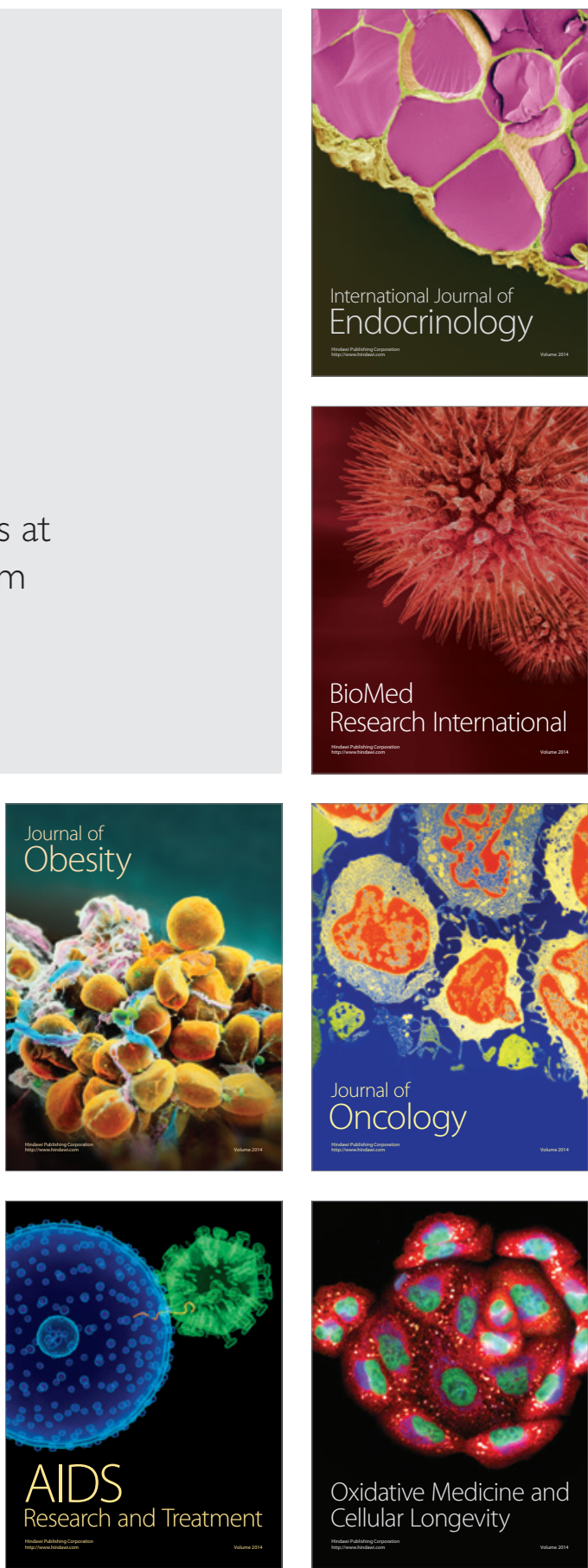